\title{
Effect of Temperature and Corrosive Environment on Cyclic Fatigue and Final Fracture Behavior of 2524 Aluminum Alloy
}

\author{
Danqing $\mathrm{Y}^{\mathrm{a}}{ }^{\mathrm{a}} \mathrm{b}$, Mingzhe $Z \mathrm{HOU}^{\mathrm{a}}$, Huiqun LIU ${ }^{\mathrm{a}, \mathrm{b}}$, \\ Bin $W_{A N G}{ }^{a, b}$ and Sheng YANG ${ }^{a, b}$ \\ ${ }^{a}$ School of Materials Science and Engineering, Central South University, \\ Changsha, Hunan, 410083, P.R. China \\ ${ }^{b}$ Key Lab of Nonferrous Materials, Ministry of Education, Central South University, \\ Changsha, Hunan 410083, P.R. China \\ *E-mail: danqing123456@126.com
}

\begin{abstract}
The effect of temperature and environment (air, humidity and $3.5 \mathrm{wt} \% \mathrm{NaCl}$ salt spray) on cyclic fatigue life and fracture mechanism on 2524 aluminum alloy was investigated by scanning electron microscopy (SEM), transmission electron microscopy (TEM) and fatiguae property testing. The results showed that temperature has a detrimental influence on cyclic fatigue life. The cyclic fatigue strength $n=10^{6}$ at elevated temperature $\left(100^{\circ} \mathrm{C}\right)$ decreased by $30 \mathrm{MPa}$ compared to that at cryogenic temperature $\left(-55^{\circ} \mathrm{C}\right)$. Moreover, temperature also remarkably affected the feature of dislocation, second-phase particles and grain boundary. The fracture surface at cryogenic temperature showed crystallographic morphology. The dominant deformation process at ambient and elevated temperature was a combination of predominantly transgranular and local intercrystalline fracture mechanism. The fractographic features revealed the fatigue crack growth behavior of the alloy in three environments, more brittle striations were observed in humidity air and salt spray. The increased crack growth rate was attributed to a combination of hydrogen embrittlement and anodic dissolution at the tip of crack.
\end{abstract}

Key Words : 2524 alloy; temperature; corrosion; cyclic fatigue; hydrogen embrittlement

\section{Introduction}

Aluminum alloys found a wide variety of uses in airplane industry because of their remarkable combination of low density, high corrosion resistance, easy workability, high electrical and heat conductivity. In the past decades, innovation and progress related to the processes and property of aluminum alloys greatly contributed to the design and manufacture of new-type civil and military aircraft. Novel aluminum alloys and tempers, (i.e. 2224T3511, C-188, 7055-T77511), have been used in Boeing 777 aircraft to obtain an improved combination of strength, ductility and damage tolerance over those alloys used in previously designed aircrafts [1].

Fatigue is a very important issue to be considered in the design of mechanical components subjected to constant and variable amplitude loading. Mechanical, metallurgical and environmental factors affected the fatigue resistance of structural components [2]. Normally fatigue is the primary cause for $80-90 \%$ of all engineering failures [3].

Corrosion pits were found to initiate crack growth in structures subjected to fatigue loading. A number of studies have addressed this by experimentally observing and modeling the growth of corrosion-initiated fatigue cracks in aluminum alloys [4-8]. A fracture mechanics approach for life prediction has been employed where the researchers have adapted the special case of pits serving as initial flaws. It has repeatedly been observed that multiple cracknucleating pits can lead to the failure of individual test samples [9-12]. Cycling heating and cooling could also result in fatigue of structure components, i.e. thermal fatigue. It is thus important that materials using for aircraft's structure have good thermal fatigue resistant performance. Abelkis [13] found that 2024 aluminum alloy performed a better fatigue property at $219 \mathrm{~K}$ than that at room temperature. Srivatsan $[14,15]$ observed similar results in 2524-T3 alloy, which has initial hardening followed by rapid softening to failure at elevated temperature.

2524 aluminum alloy is a relatively new $\mathrm{Al}-\mathrm{Cu}-\mathrm{Mg}$ alloy and used as fuselage skin replacement of 2024 alloy [16,17]. The objective of this paper is to document the influence of temperature and corrosion environment on fatigue property of 2524 aluminum alloy. The high-cycle fatigue properties and final fracture characteristics of the alloy at four temperatures are evaluated. The fatigue crack propagation of the alloy in humid air and salt spray were investigated compared to the test conducted in the lab air.

\section{Experimental}

2524 alloy for this study was provided by Northeast Light Alloy Co. Ltd. with final condition being $2.2 \mathrm{~mm}$ thick alclad sheet. The chemical composition of the material is listed in Table 1. Axial test specimens were machined from as-received 2524-T4 alloy plate according to China standard GB 3075-82 for stress amplitude- 
Table 1 The chemical composition of 2524 alloy (wt $\%)$

\begin{tabular}{lllllll}
\hline & $\mathrm{Cu}$ & $\mathrm{Mg}$ & $\mathrm{Mn}$ & $\mathrm{Fe}$ & $\mathrm{Si}$ & $\mathrm{Al}$ \\
$\mathrm{wt} \%$ & $4.0-4.23$ & $1.4-1.42$ & $0.56-0.6$ & $\leq 0.08$ & $\leq 0.06$ & bal. \\
\hline
\end{tabular}

controlled high-cycle fatigue test, as seen in Figure 1 and Figure 2 , which was prepared for fatigue life testing and fatigue crack propagation rate testing respectively.

All fatigue tests were loaded up to failure on a fully automated, closed-loop servohydraulic mechanical test machine (INSTRON-8032), and specimens were parallel (longitudinal) to the rolling direction.

The fatigue life tests were carried out at four different temperatures $\left(-55^{\circ} \mathrm{C}, 25^{\circ} \mathrm{C}, 100^{\circ} \mathrm{C}, 150^{\circ} \mathrm{C}\right)$ in attached furnace filled with air, via tension-tension loading mode at different stress level $(180 \mathrm{MPa}$ to $300 \mathrm{MPa})$ with stress ratio $\mathrm{R}=0.1$ at frequency $\mathrm{f}=20 \mathrm{~Hz}$, fatigue lives were counted by the computer attached to the tester.

Fatigue crack propagation tests at different environment (air, humidity and $3.5 \mathrm{wt} \% \mathrm{NaCl}$ salt spray) were carried out at INSTRON-8032 by using middle tension mode, M(T) (Figure 2) with environment chamber attached for providing corrosion environment. Samples were pre-cracked under mode-I stretched to $0.1 \mathrm{~mm}$ and subjected to constant tension (i.e. progressive increase in $\Delta K$ with crack extension) maintaining a load ratio of 0.1 . The sinusoidal loading cycles were applied at a frequency of $10 \mathrm{~Hz}$. The length of fatigue crack was measured by an optical microscope $( \pm 1 \mu \mathrm{m})$ attached on the Instron tester. The following equation was used to determine stress intensity factor $\Delta K$.

$$
\Delta K=\frac{\Delta P}{B} \sqrt{\frac{\pi \alpha}{2 w} \sec \frac{\pi \alpha}{2}}
$$

Where, $\mathrm{P}$ is load, $\mathrm{B}$ and $\mathrm{w}$ is sample thickness and width, $\alpha=2 \mathrm{a} / \mathrm{w}$, a is crack length.

Fracture surface of the cyclically deformed and failed specimens were examined by KYKY-2800 type scanning electron microscope (SEM) to characterize the topographic features of the fatigue fracture surface. Disks of $3 \mathrm{~mm}$ in diameter and around $0.5 \mathrm{~mm}$ in thickness were cut from the fatigue test samples near the fracture surface for TEM observation. Electropolished solution was a mixture $\mathrm{HNO}_{3}$ and methanol (1:3 in volume). TEM foils were examined by TecnaiG ${ }^{2} 20$ transmission electron microscope operating at $200 \mathrm{kV}$.

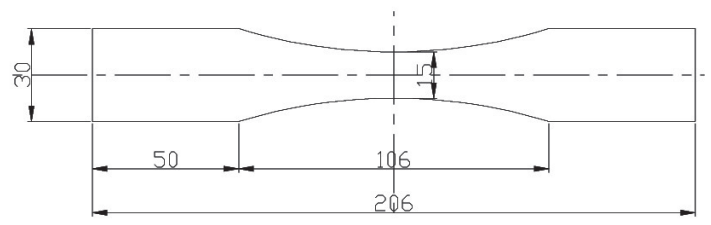

Figure 1 Smooth rectangular sample for fatigue test $(\mathrm{mm})$

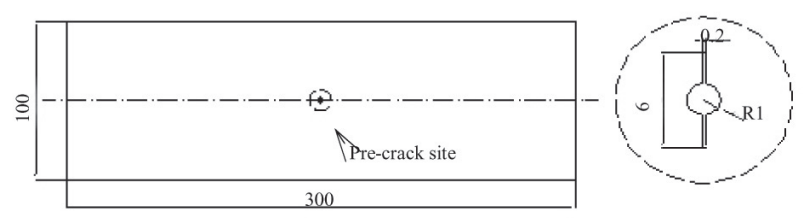

Figure 2 The sample for fatigue crack propagation test $(/ \mathrm{mm})$

\section{Results and discussion}

\subsection{The influence of temperature}

3.1.1 S-N curves: S-N curves for as-received 2524 alloy at different temperatures $\left(-55^{\circ} \mathrm{C}, 25^{\circ} \mathrm{C}, 100^{\circ} \mathrm{C}, 150^{\circ} \mathrm{C}\right)$ were given in Figure 3. It can be found that fatigue life $\left(\mathrm{N}_{f}\right)$ is inversely proportional to the temperatures at the same stress level. The cyclic fatigue strength of $10^{6}$ cycles at elevated temperature $\left(100^{\circ} \mathrm{C}\right)$ decreased by $30 \mathrm{MPa}$ than that at cryogenic temperature $\left(-55^{\circ} \mathrm{C}\right)$. The fatigue behavior of the alloy at $150^{\circ} \mathrm{C}$ at higher stress level is discussed below.

3.1.2 Fracture analysis: Figures. 4-6 show fractographic morphology of different stages of crack growth in the 2524 alloy studied together with fatigue life $\mathrm{N}_{f}$ The fatigue life were tested at $-55^{\circ} \mathrm{C}, 25^{\circ} \mathrm{C}, 100^{\circ} \mathrm{C}$ and $150^{\circ} \mathrm{C}$.

Figure 4 illustrates the cases that the crack originated from surface at different temperatures. Normally, the crack source comes from the surface, where the maximum tension stress occurs. For the alclad alloy, the crack initiated at the pure aluminum layer because of its lower yield strength [18,19]. Figure 5 illustrates the fatigue crack propagation area. As shown, the fracture surface at cryogenic temperature exhibits a crystallographic fracture pattern, which was not observed at room temperature and above. The overload region (Figure 6) of all samples were similar to static

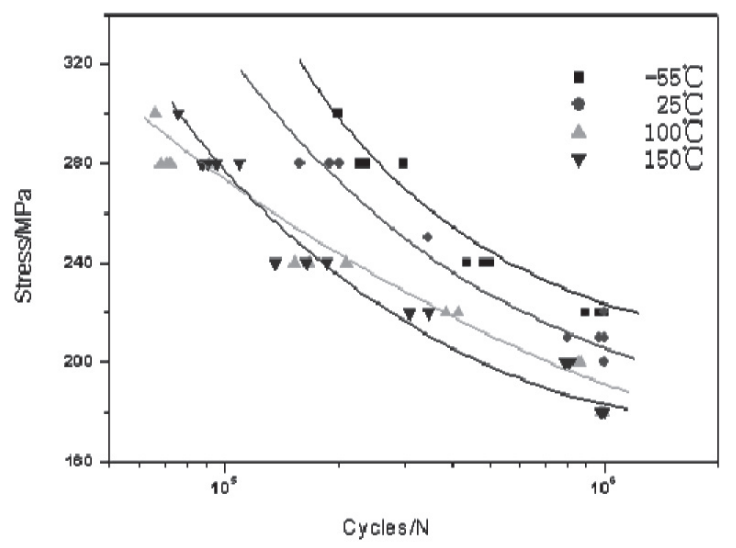

Figure 3 Fatigue S-N curves of 2524 alloy at different temperatures
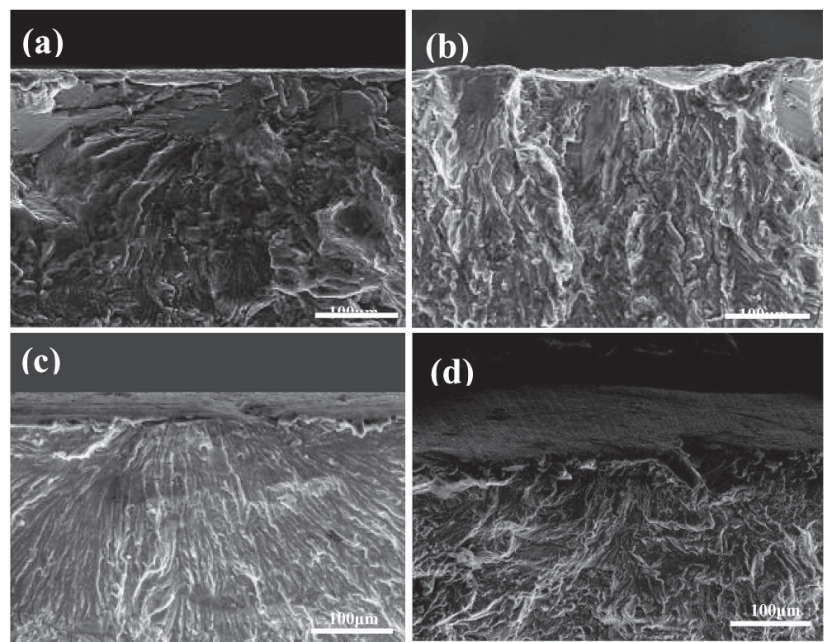

Figure 4 Fractograph of fatigue crack initiation zone of 2524 alloy at $\sigma_{\max }=280 \mathrm{MPa}$, with (a) $-55^{\circ} \mathrm{C} \quad \mathrm{N}_{f}=297541$ (b) $25^{\circ} \mathrm{C} \quad \mathrm{N}_{f}=111957$ (c) $100^{\circ} \mathrm{C} \quad \mathrm{N}_{f}=72198$ and (d) $150^{\circ} \mathrm{C} \quad \mathrm{N}_{f}=90688$ 
tensile fracture surface, which comprised of macroscopic voids and dimples. Dimples of sample tested at cryogenic are shallower than others, which exhibits brittle fracture feature. With the increase of temperature, dimples were getting deeper.

3.1.3 TEM microstructure: Figure 7 illustrates the TEM images of 2524 alloy after fatigue test at different temperature. As seen in Figure 7 , the dislocation density is lower at cryogenic temperature than that at room temperature because more energy is needed for the generation and movement of dislocation at low temperature. With the increase of temperature, more dislocations were easily to move and then piled up at grain boundary; small cracks formed in consequence after applying cyclic stress.

3.1.4 Effect of temperature on fatigue mechanism: During the fatigue process, the formation of fatigue crack took most of the fatigue life, in order to analyze the effect of temperature on the fatigue life, here we focus on micro-crack formation as a function of temperature. According to the dislocation slipping mechanism, there were three stages in a fatigue process: (a) fine slip lines formed by the motion of dislocations, (b) formation of slip band; (c) formation of micro-crack. In this paragraph, the microrheological stress mechanism was introduced to analyze the effect of temperature on the fatigue properties of the alloy [20,21], The
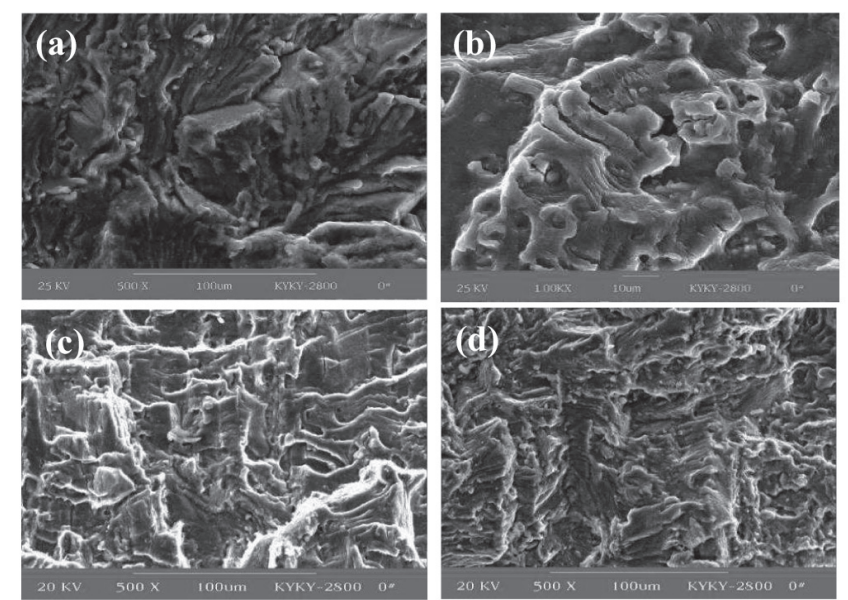

Figure 5 Fractograph of fatigue crack growth of 2524 alloy at $\sigma_{\max }=280 \mathrm{MPa}$, with (a) $-55^{\circ} \mathrm{C} \quad \mathrm{N}_{f}=297541$ (b) $25^{\circ} \mathrm{C} \quad \mathrm{N}_{f}=111957$ (c) $100^{\circ} \mathrm{C} \mathrm{N}_{f}=72198$ and (d) $150^{\circ} \mathrm{C} \mathrm{N}_{f}=90688$
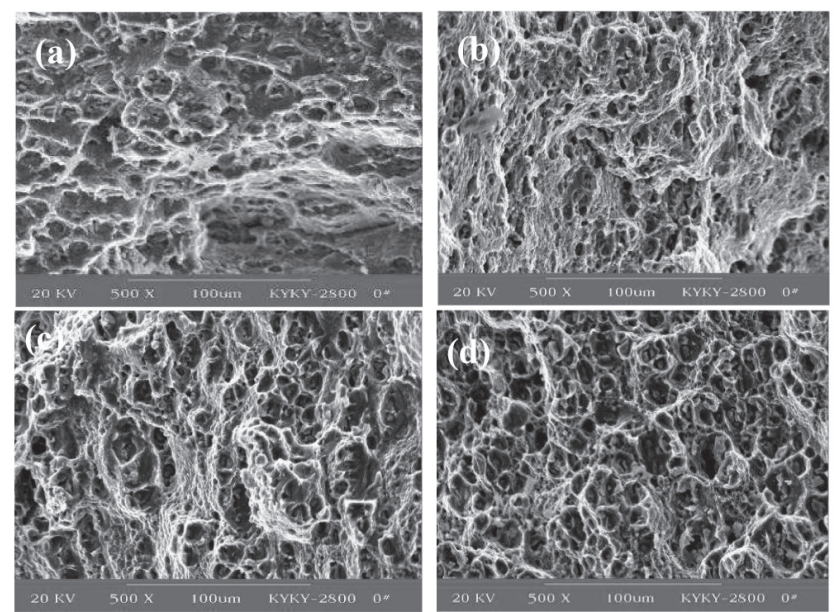

Figure 6 Fractograph of rapid crack growth zone of 2524 aluminum alloy at $\sigma_{\max }=280 \mathrm{MPa}$, with (a) $-55^{\circ} \mathrm{C} \mathrm{N}_{f}=297541$ (b) $25^{\circ} \mathrm{C}$ $\mathrm{N}_{f}=111957$ (c) $100^{\circ} \mathrm{C} \quad \mathrm{N}_{f}=72198$ and (d) $150^{\circ} \mathrm{C} \quad \mathrm{N}_{f}=90688$ stress $\tau$ is given by [22]:

$$
\tau=\tau_{p}+\tau_{s}+\tau_{I}+\tau_{J}+\tau_{D}
$$

where $\tau_{\mathrm{P}}$ is the lattice resistance, $\tau_{\mathrm{S}}, \tau_{\mathrm{I}}, \tau_{\mathrm{J}}$ and $\tau_{\mathrm{D}}$ are the resistance caused by dislocation stress field, dislocation intersect, jogging, and point defects respectively. The $\tau_{\mathrm{S}}, \tau_{\mathrm{I}}$ are long-range resistance which are insensitivity to temperature, while $\tau_{\mathrm{J}}$ and $\tau_{\mathrm{D}}$ are shortrange resistance sensitive to temperature. At ambient temperature, both the lattice resistance $\tau_{\mathrm{p}}$ and short range resistance are small where movement of dislocations to be ease. However the pileup of dislocations at grain boundary would cause local stress concentration and .micro-crack formation. On the other hand, the thermal vibration of the lattice at cryogenic temperature is decreased, where the long-range resistance being remained,
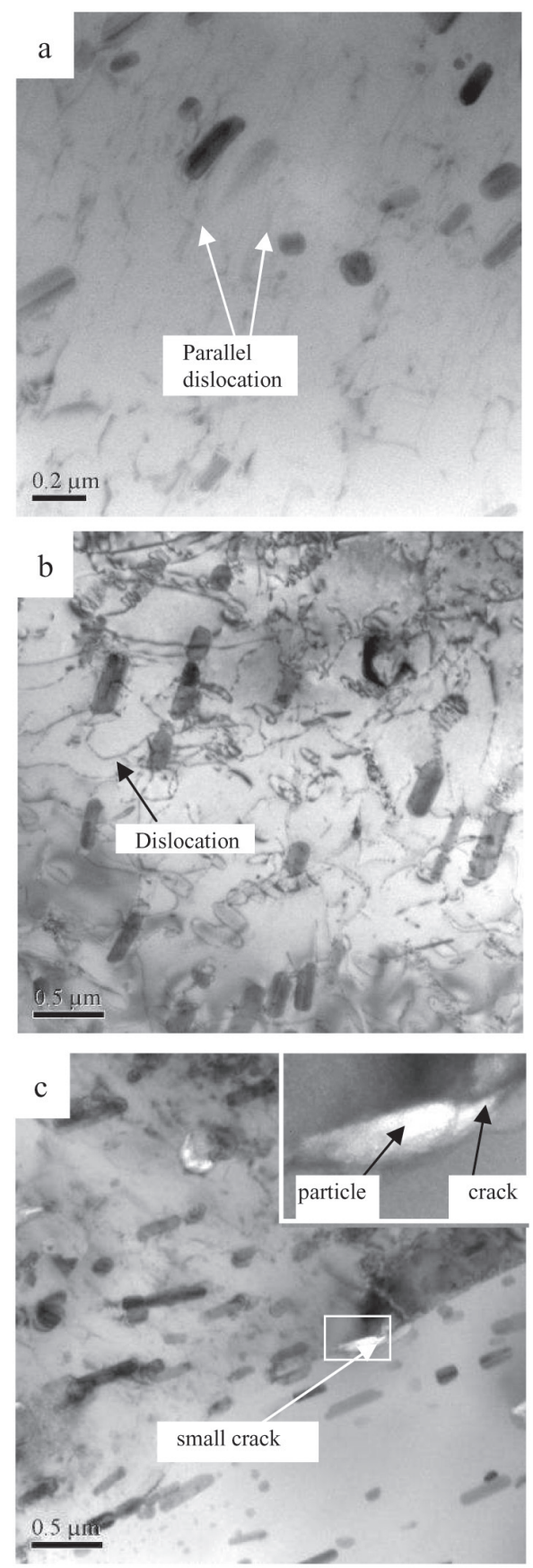

Figure 7 TEM of $2524 \mathrm{Al}$ alloy at $\sigma_{\mathrm{Max}}=280 \mathrm{MPa}$

(a) $-55^{\circ} \mathrm{C} \quad \mathrm{N}_{f}=297541$ (b) $25^{\circ} \mathrm{C} \quad \mathrm{N}_{f}=111957$ (c) $100^{\circ} \mathrm{C} \quad \mathrm{N}_{f}=72198$ 
while temperature sensitive factors $\tau_{\mathrm{J}}$ and $\tau_{\mathrm{D}}$ increased, causing larger lattice resistance. Compared with the case of the ambient temperature, the density of dislocations is decreased at the same stress level (Figure 7). Lower density of dislocations means less micro stress concentration of the alloy, so the time of micro-crack formation was longer. Moreover, the dislocation accumulation rate at grain boundaries tends to slower, which means longer time for the dislocations to move in neighbor grains. At higher temperature, the energy for dislocation to start moving decreased, and dislocations movement occurred and piled up at the grain boundaries. After fewer loading times, they could cause the stress concentration and then resulted in micro-cracks (Figure 7c), which led to a short fatigue life at the same stress level compared with the case of lower temperature.

As known, the slip bands could be recovered during the fatigue process, but at higher temperatures, the formation of an oxide of $\mathrm{Al}_{\mathrm{x}} \mathrm{O}_{\mathrm{y}}$ will occur in a short time, by synergism of temperature and oxygen in the ambient air, and caused a reduction of the recovery of the slip bands, which produced unrecovery plastic deformation of the alloy. The synergism mechanism of all the factors mentioned above caused a shorter fatigue life of alloy at higher temperatures.

It is worth to mention that, at higher stress level, the alloy has a better fatigue property at the $150^{\circ} \mathrm{C}$ than that at $100^{\circ} \mathrm{C}$. During the fatigue process at $150^{\circ} \mathrm{C}$, higher temperature and stress induced the precipitation of second phase. The increase of dislocation moving resistance by precipitates improved the fatigue performance at $150^{\circ} \mathrm{C}$ [23]. However, at lower stress level, by the precipitates coarsening during the long period fatigue process, the mechanism mentioned at last paragraph become the dominate mechanism.

According to the work of Cedirc [24], for naturally aged 2024 $\mathrm{Al}-\mathrm{Cu}-\mathrm{Mg}$ alloy, while the fatigue stress was large enough, the dislocation can cut through the GP zone and form the fracture surface with steps. At cryogenic temperature, because of high resistance to dislocations' movement, it is very hard for dislocation slip to transmit from one grain to neighbor grains. and the different grains have different orientations, the crack will propagate along a route with least resistance so the cryogenic fracture shows coarsening steps pattern. With the increase of temperature, dislocations' mobility increase, the stress concentration caused by the piled up dislocations near the grain boundaries could start more slip bands in the neighbor grains, and the nearly grains with lower deflexion angle become easier to crack, so the fracture morphology shown smoother patterns.

As seen in Figure 4 to Figure 6, the cryogenic fracture surface is characterized by some cleavage feature and plates (Figure $4 \mathrm{a}$ and Figure 5a). At ambient temperature and higher temperatures, stripes were observed paralleling the cracking direction, and some micro-cracks can be seen near the grain boundaries especially at high temperature. That is because at higher temperatures, the binding force of atoms decreased, so the cracks were easily formed at the area. Large amount of oxide were observed at the fracture surface, after treated at $150^{\circ} \mathrm{C}$.

3.1.5 Thermal activation model: According to Baxter [25], during a fatigue test, the average rate of development of fatigue damage (D) is given by

$$
D=N_{f}^{-1}
$$

Where $N_{f}$ is the number of cycles to failure.

Considering process of fatigue damages can be treated as a thermally activated process [25], then for a constant cyclic stress, the Arrhenius equation should apply:

$$
D=N_{f}^{-1}=N_{0}^{-1} \exp \left(\frac{-Q}{R T}\right)
$$

Where $\mathrm{T}$ is the absolute temperature, $\mathrm{R}$ is the gas constant ( 8.31 $\mathrm{J} / \mathrm{deg}$ mole), $\mathrm{Q}$ is the activation energy, and $\mathrm{N}_{0}$ is the fatigue life when $\mathrm{Q}<<\mathrm{RT}$ and thermal activation which is not important here. When this equation is applied to our fatigue data at three constant cyclic stresses (220, 240, $280 \mathrm{MPa}$; dotted lines in Figure 1), we obtain the Arrhenius plots shown in Figure 8.

At each stress level, the experimental data are in good agreement with Eq. (4), confirming that the fatigue damage process is thermally activated.

The calculated values of activation energy, which are also shown in Figure 8, decrease with increasing cyclic stress $\sigma$ (Figure 9), obeying the simple relationship, which is the same as that originally proposed many years ago [26, 27]

$$
Q=Q_{0}-\beta \sigma
$$

Where $\mathrm{Q}_{0}$ is the activation energy in the absence of an applied stress and $\beta$ is the activation volume. More specifically from Figure 9,

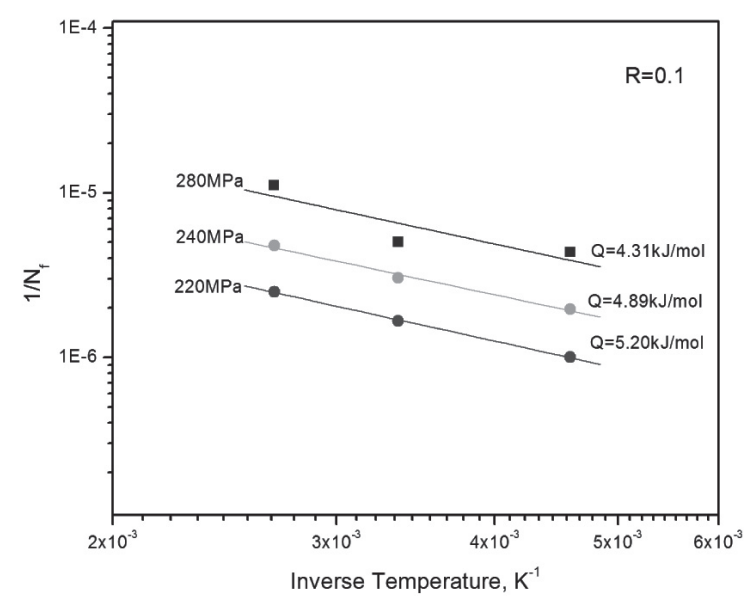

Figure 8 Arrhenius plot of the rate of fatigue damage $\left(N_{f}^{-1}\right)$ vs reciprocal temperature for 2524 alloy. Data points correspond to constant cyclic stresses of $220,240,280 \mathrm{MPa}$, as indicated by lines in Figure 3.

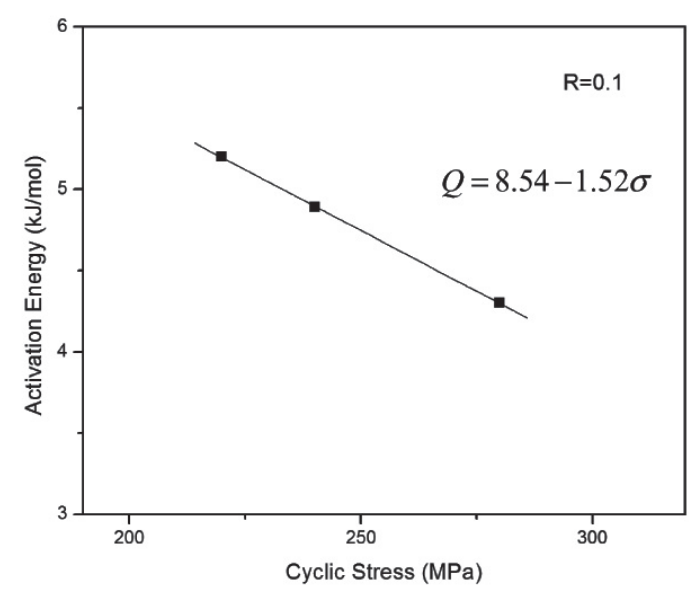

Figure 9 Effect of cyclic stress on the activation energy for fatigue damage in 2524 alloy 


$$
Q=8.54-1.52 \sigma \mathrm{kJ} / \text { mole for } \sigma \text { in } \mathrm{MPa}
$$

Thus, the thermally activated fatigue process is stress assisted and obey the following equation:

$$
N_{f}=N_{0} \exp \left(Q_{0}-\beta \sigma\right) / R T
$$

An interesting corollary is that,

$$
\beta \sigma=Q_{0}-R T \ln \left(N_{f} / N_{0}\right)
$$

the fatigue strength corresponding to a specific fatigue life decrease linearly with increasing temperature. These analysis demonstrate quite clearly that the fatigue damage of 2524 alloy is thermally activated. But this is based on assumption that no simultaneous thermally induced changes in the microstructure, which needs further research works to prove.

\subsection{The influence of corrosion environment}

3.2.1 Fatigue crack propagation: Fatigue crack propagation rate of $2524 \mathrm{Al}$ alloy in three different environments (lab air, humid air and salt spray) were shown in Figure 10 and Figure 11. The humid air and salt spray environment accelerate the fatigue crack propagation. At the first stage of fatigue crack propagation, humid air accelerates the FCP significantly. The FCP rate in humid air is almost two times than that in ambient air. While at the steadystate stage, the FCP in humid air is $40 \%$ faster than that in ambient air. Based on the Paris relationship (Eq. 9), an environment factor $\gamma$ was introduced here for amendment, seen in Eq. 10. linear regression fitted results of the environment factor $\gamma$ were 1.324 and 1.528 of humid air and salt spray environment respectively.

$$
\begin{aligned}
& d a / d N=c \Delta k^{n} \\
& d a / d N=\gamma c \Delta k^{n}
\end{aligned}
$$

3.2.2 Fracture morphology: The SEM observation of fatigue fracture surface $\left(\Delta \mathrm{K}=10 \mathrm{MPa}^{*} \mathrm{~m}^{1 / 2}\right)$ is presented in Figure 12. It can be seen that in ambient air the striations were evenly spaced indicating stable growth of cracks through the microstructure. In contrast to the case above, the fractographs of tested samples in the other two environments show more brittle feature, and some microcracks were observed as pointed by white arrows in Figure 12. For the salt spray tested samples, the fractured surface was covered by a layer of corrosion products. The striations exhibit brittleness feature. The width between the striations in salt spray environment was the largest at the same stress level, which is consist to the FCP rate results (Figure 10, 11).

\subsection{Fatigue Mechanism}

During the fatigue process, plastic deformation accumulated at the plastic zone beyond the fatigue crack tips, then caused the crack propagation and the plastic deformation striations formed.

According to the hydrogen embrittlement theory [28, 29], if there was water vapor in the environment, some reactions would occur at the fresh fracture surface during the fatigue process as follows:

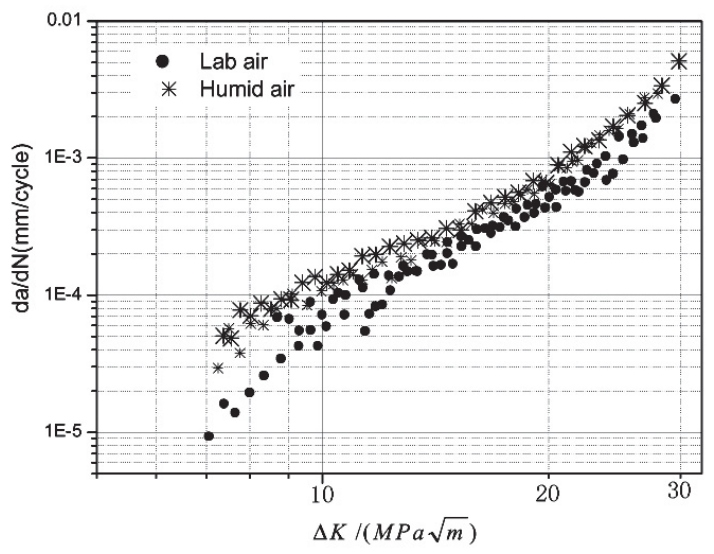

Figure 10 Crack growth rate of alloy in lab air and humid air

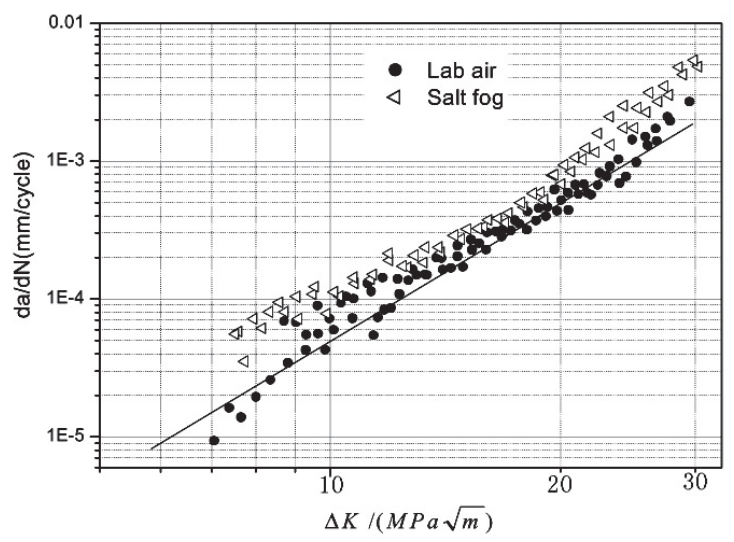

Figure 11 Crack growth rate of alloy in lab air and salt spray

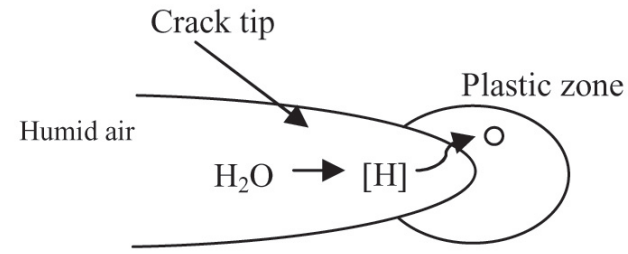

Figure 13 Hydrogen embrittlement principle model in humid air
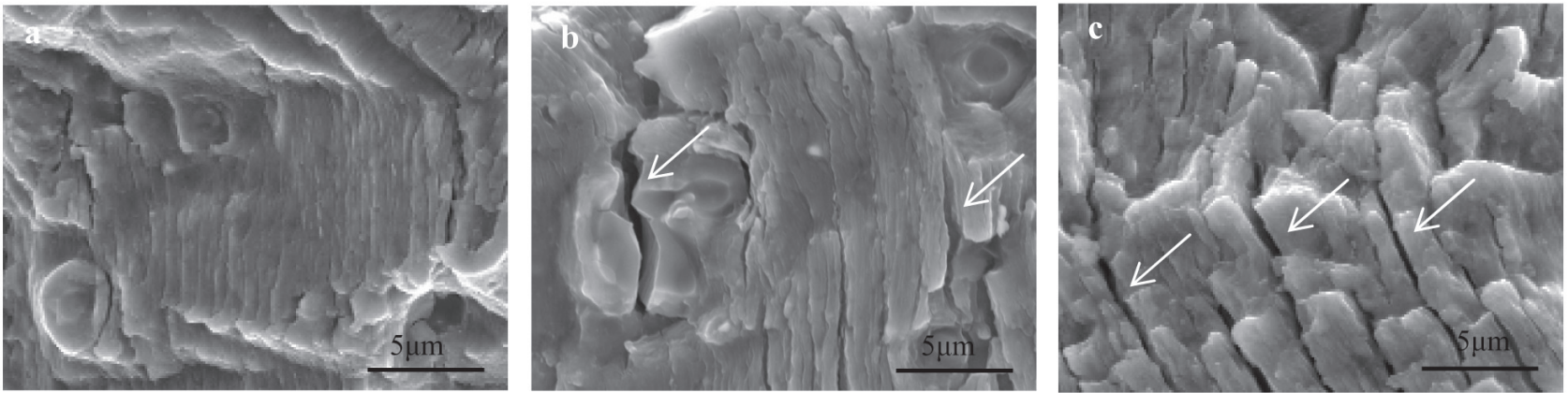

Figure 12 Fatigue fractographs for 2524 alloy, where $\Delta \mathrm{K}=10 \mathrm{MPa}^{*} \mathrm{~m}^{1 / 2}$, with(a) in lab air; (b) humid air; and (c) salt spray 


$$
\begin{aligned}
& \mathrm{Al} \rightarrow \mathrm{Al}^{3+}+3 \mathrm{e} \\
& 2 \mathrm{Al}^{3+}+6 \mathrm{H}_{2} \mathrm{O} \rightarrow 2 \mathrm{Al}(\mathrm{OH})_{3}+6 \mathrm{H}^{+} \\
& \mathrm{H}^{+}+\mathrm{e} \rightarrow \mathrm{H}
\end{aligned}
$$

Figure 13 gives a schematic of hydrogen embrittlement during the fatigue process. The activated $\mathrm{H}$ atoms could diffuse through dislocations to the tip of cracks, caused the brittleness at the plastic zone beyond the crack tips then resulted in the decreased stress for the crack propagation, which increased the FCP rate simultaneously.

At the initial stage of crack propagation, lower FCP rate led to less surface, so the exposed fresh surface per cycle was very limited, which means that the amount of activated $\mathrm{H}$ atoms transporting to the plastic zone per cycle was high. So the effect of hydrogen embrittlement on the FCP rate at lower stress intensity factor range is markable (Figure 10). However, at higher stress intensity factor range, FCP rate was faster, the amount of activated $\mathrm{H}$ atoms permeated to the plastic zone per cycle became smaller, which caused the effect of hydrogen embrittlement on the FCP rate at high stress less significant.

Similar to the fatigue propagation in the humid air, the fresh fracture surface exposed in salt spray environment, in which cell reaction occurred during the fatigue process, as presented in Eq. 12, the salt spray is the electrolyte, the fresh surface of the alloy was the anode of corrosion micro-battery. The anode metal dissolved into the electrolyte which caused pits at the surface of alloy. The stress concentration at the pits accelerated the crack propagation rate. In another hand, the dissolving occurring at the crack tip promoted the hydrogen brittleness, and then increases the FCP rate of the alloy. The co-action of pit stress concentration and hydrogen brittleness contribute to the highest FCP rate in this experiment.

$$
\begin{aligned}
& \mathrm{Al} \rightarrow \mathrm{Al}^{3+}+3 e(\text { anodic }) \\
& H^{+}+e \rightarrow H(\text { canthodic })
\end{aligned}
$$

\section{Conclusions}

By the use of fatigue test machine, SEM and TEM, the fatigue performance and fracture behavior of 2524 aluminum alloy were studied at four temperatures and in three classical environment (ambient air, humid air and salt spray), we can conclude as follows: (1) The fatigue life of the alloy increased with the decrease of temperature, the better fatigue performance at lower temperatures is due to higher dislocation motion resistance. (2) Fatigue damage in 2524 alloy at elevated temperatures is thermally activated, and the effective activation energy for each mechanism is reduced by increasing the applied cyclic stress, obeying a linear relationship. (3) The fatigue crack propagation rate increased in humid and salt spray environment, environment factor $\gamma$ of meliorated Paris relationship is 1.324 and 1.528 for humid air and salt spray environment respectively. (4) Hydrogen brittleness mechanism of activated $\mathrm{H}$ atoms transporting to the plastic zone is the main reason for the FCP acceleration in humid air environment; and the acceleration of FCP rate in the salt spray environment is due to the hydrogen brittleness and anode dissolving synergism.

\section{Acknowledgements}

This research was jointly supported by The National Key Basic Research Program of China (grant Number, 2005CB623705) and China Aluminum Company Research Program (grant Number CHALCO-2007-KJ-09). The authors would like to thank both of them.

\section{References}

[1] Payne J. MIAC Newsl; December: p.4., (1995).

[2] Pellpoux R. M., In: Proceedings of Conference fatigue. Montreal; (1993).

[3] Ilston J. M., Dinwoodie J. M., Smith A. A., Concrete, timber and metals, New York: Van Nostraand Reinhold; (1979).

[4] Du Quesnay D. L., Underhill P. R., Britt H. J., Int. J. Fatigue, 25: p.371 (2003).

[5] Medved J. J., Breton M., Irving P. E., Int. J. Fatigue; 26: p.71 (204).

[6] Sankaran K.K., Perez R., Jata K.V., Mater. Sci. Eng; A297 p.223 (2001).

[7] Dolley E.J., Lee B., Wei R.P., Fatigue Fract. Eng. Mater. Struct.; 23: p.555 (2000).

[8] Zamber J.E., MS Thesis, Purdue University; (1997).

[9] Bray G.H., Bucci R.J., Colcin E.L., Kulak M., ASTM STP 1298. ASTM; p.89 (1997).

[10] Perez R. Corrosion/fatigue metrics. ICAF97 symposium on fatigue in new and ageing aircraft, Edingburgh, Scotland, p.215 (1996).

[11] Pao P.S., Gill S.J., Feng C.R., Scripta Mater.; 43: p.391 (2000).

[12] Tuegel E.J., Report AFRL-VA-WP-TR-2003-3088. Air Force Research laboratory, Air Force Material Command, WrightPatterson Air Force Base, Ohio; (2003).

[13] Abelkis P. B., Harmon M. B., Hayman E. L., ASTM Special Technical Publication, p.257 (1985).

[14] Srivatsan T. S., Kolar D., Magnusen P., Materials Science and Engineering A, 2001,: p.118 (314).

[15] Srivatsan T. S., Kolar D., Materials and Design, 23: p.129 (2002).

[16] Starke E. A. Jr., Staley J. T., Prog. Aerospace Sci., 32: p.131 (1996).

[17] Cassada W., Liu J., Taley J., Advanced Materials Processes, 162: p.27 (2002).

[18] Edwards P. R., Earl M. G., RAE Technical Report of Aeronautical Research Council, Farnborough, p.1361 (1977).

[19] Truckner W. G., Staley J. T., Bucci R. J., et a1., USAF Technical Report AFML-TR-96169, 10 (1976).

[20] Xu H., Fatigue Strength [M], Beijing, Higher Education Publishing Company, (1988).

[21] Feng D., Metal Physics[M], Beijing, Science Press, (1999).

[22] Basinski Z. S., Christian J. W., Advanced Cryogenic Engineering, 2: p.90 (1954).

[23] Yang S., Study on the microstructure of 2E12 aluminum alloy during the attended time[D]. Central South University, Changsha, China. (2008).

[24] Cedric G., Christine S. B., Jean P., et. al., Scripta Materialia, 53: p.1333 (2005).

[25] Baxter W. J., Proc. 10th Int. Conf. on Composite Materials, C. A. Poursatip and K. N. Street, eds., Woodhead Publishing Limited, Abington, England, vol.4, p.109 (1995).

[26] Cottrell A. H., Dislocations and Plastic Flow in Crystal, Clarendon Press, Oxford, United Kingdom, (1953).

[27] Feltham P., Phil. Mag., vol.2, p.584 (1957).

[28] Stanzl-Tschegg S. E., Mayer H. R., Tschegg E. K., Materials Science and Engineering A, p.45 (1991).

[29] Harvey C., Voris and Min-Ten Jahn, Journal of Material Science, 25: p.4708 (1989). 